\title{
A REVIEW OF PAPERS ABOUT BLOCK PROGRAMMING FROM THE WORKSHOP ON COMPUTING AT SCHOOL
}

\author{
Gilberto Amado de Azevedo Cysneiros Filho, Neiton Carvalho da Silva, \\ \& Barbara Silva Morais \\ Universidade Federal Rural de Pernambuco (UFRPE), Departamento de Estatística e Informática \\ (DEINFO), Street Manuel de Medeiros, s/n-neighborhood: Dois Irmãos, city: Recife - UF: PE, \\ ZIP CODE 52171-900 (Brazil)
}

\begin{abstract}
This paper describes a survey to identify how Block Programming is being used in Brazilian schools. The motivation of this research is to provide us with data and insights to support the research project on Block Programming and Computational Thinking in Schools whose goal is to investigate and create a proposal for how Block Programming can be inserted into the school curriculum. The relevance of this research is that the school should prepare the students for the skills (creativity, programming, problem solving, abstraction and innovation) demanded by the job market and for further education (e.g. university courses and qualification courses). In particular, in Brazil the curriculum of schools is governed by a normative document called the Common National Curricular Base (Base Nacional Comum Curricular - BNCC). The BNCC defines that the school curriculum should enable the student to have the following competencies: (1) knowledge; (2) scientific, critical, and creative thinking; (3) cultural repertoire; (4) communication; (5) digital culture; (6) work and life project; (7) argumentation; (8) self-knowledge and self-care; (9) empathy and cooperation; and (10) responsibility and citizenship. Some of these skills can be achieved by learning Block Programming aligned with Computational Thinking instruction. The importance of learning programming in school is justified by the increased use of technology in modern society and the need to be prepared to create and use technological solutions that involve programming and computing. The BNCC highlights that the skills developed by students should be organized by offering different curricular arrangements, according to the relevance to the local context and the possibilities of the education systems. This can be applied in a multidisciplinary way through block programming based on computational thinking in basic education. A literature review was conducted of papers published in the area of block programming at the Workshop on Informatics at School (WIE) between the years 2016 to 2019. The choice of this event is due to the fact that it has been standing out over the years as a forum for discussions where works in the area of digital technologies of information and communication (TDIC) in formal and non-formal spaces of education have been disseminated. During this period we identified papers that describe the use of several environments of Block Programming (e.g. Scratch) and several experiences and proposals of how to insert Block Programming in the students' education.
\end{abstract}

Keywords: Block programming, computational thinking, BNCC, workshop of computing at school, workshop de informática na escola (WIE).

\section{Introduction}

In modern society, the growing use of technologies proves the importance of learning programming at school. In this context, we have the Brazilian educational planning that outlines strategies for the insertion of programming in basic education. This strategic planning was introduced in the reformulation of the Common National Curricular Base in the year 2018, as we have the insertion of the term Computational Thinking (CP) in basic education. According to [Wing, 2006] the term CP is broadly defined as a methodology of problem solving, systems development through basic concepts of Computer Science, such as logical reasoning.

Given this, it was verified that the teaching of programming for basic education through playful and attractive approaches needs to be taken into consideration. In this context, Visual Programming Languages (VPL), that is, languages that include visual expressions" [Burnett, 1999]. Using this paradigm many tools have developed artifacts for teaching visual programming by "plug-in blocks" with the objective 
of facilitating the teaching-learning process. Since then, block programming discusses fundamental approaches that result in the development of the PC skills addressed in the BNCC. And according to [Silva, Freitas, 2021], the 10 competencies of the BNCC are interrelated, targeting the curricular components of all basic education in Brazil, and interconnecting with the construction of knowledge and skills in the student's academic and professional training.

This work aimed to identify strategies developed by block programming used in the teaching-learning process that stimulate the development of PC through a Systematic Literature Mapping (SLM) as methodology. It aimed to clarify the following research question: How does block programming contribute to the teaching of programming by stimulating PC development through different tools.

\section{Related papers}

Several papers present studies that seek to identify how CP skills can be developed with the teaching of visual programming. According to Bombasar et al. (2015) conducted a systematic review of the literature with the aim of identifying the main tools that have been used to address the development of PC teaching from 2006 to 2015 .

According to (Morais, 2020), many students have difficulties in learning to program and the scientific community has been developing several proposals to overcome this challenge. And as a result it was indicated that the main tools used are those that use visual programming.

\section{Methodology}

According to [Petersen et al. 2015] the methodological procedure of systematic literature mapping (SLM) is a method that allows categorizing primary studies seeking results on the state of the art of a given subject. To identify the strategies developed by block programming used in the teaching-learning process in Brazil, the SLM method was adopted.

\subsection{Search strategy}

The data collection was carried out from October 29, 2020 to January 15, 2021, and it was used as a base the papers published in the Workshop on Informatics at School (WIE), this national base gathers numerous publications on Informatics in Education from Brazil from all years available at: $<$ https://br-ie.org/pub/index.php/wie/issue/archive $>$.

\subsection{Inclusion and exclusion criteria}

Papers published between the years 2016 to 2019 were defined as inclusion criteria, as in previous surveys identified a scarcity of papers detailing block programming teaching in previous years. Another criterion to be considered were papers with technological descriptors parallel to the teaching of computing with approaches linked interdisciplinarily using block programming containing keywords such as: computational thinking, App Inventor, Scratch, Scratch Jr, inclusive education, pedagogical practices in teaching computing, teacher training and BNCC. Two stages were performed: the first stage of screening the papers were chosen through the title and abstract as shown in Table 1.

Table 1. Stage 1 - Proceedings of the Workshop on Computing at School from 2016 to 2019.

\begin{tabular}{|c|c|}
\hline Year(all) & DOI \\
\hline 2016(4) & 10.5753/cbie.wie.2016.359;10.5753/cbie.wie.2016.436;10.5753/cbie.wie.2016.786; 10.5753/cbie.wie.2016.958 \\
\hline $2017(9)$ & $\begin{array}{l}\text { 10.5753/cbie.wie. } 2017.402 ; 10.5753 / \text { cbie.wie. } 2017.362 ; 10.5753 / \text { cbie.wie. } 2017.1159 ; 10.5753 / \text { cbie.wie. } 2017.382 ; \\
10.5753 \text { /cbie.wie. } 2017.432 ; 10.5753 \text { /cbie.wie. } 2017.538 ; 10.5753 \text { /cbie.wie. } 2017.805 ; 10.5753 / \text { cbie.wie. } 2017.1119 ; \\
10.5753 \text { cbie.wie. } 2017.1174\end{array}$ \\
\hline $2018(2)$ & $10.5753 /$ cbie.wie. $2018.41 ; 10.5753 /$ cbie.wie.2018.195 \\
\hline 2019(14) & 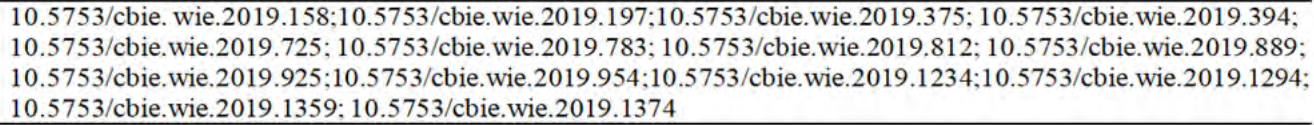 \\
\hline
\end{tabular}

The other step was data extraction whereby the papers were fully analyzed considering the research question against the validation criteria as shown in Table 2. 
Table 2. Criteria used for data extraction in the selected papers.

\section{Criteria for data extraction}

Tool used; PC skills developed; Pedagogical Approaches; Other Information (Place, Year, Teaching Level, Teaching Unit, etc.)

In the end a total of 29 papers were analyzed, and among it significant works were revealed relating block programming to cross-cutting themes such as: Therapy of Psychiatric Patients [Leal, 2019]; Teaching robotics with indigenous people [Segundo, 2019] in basic education in Brazil; Several papers dealing with combating school dropout [Santos, 2019] as an example; Building a humanoid [Amorim, 2016] in a public school in Recife; Financial education with block programming [Oliveira Farias, 2019].

\section{Results and discussion}

Despite the expansion of the term CP as of 2006, we found that the BNCC only addresses the insertion of CP in 2018, leaving a 12-year gap in the knowledge about programming in elementary education. In this context, we observed that from 2019 we had a significant increase in works that inserted programming in blocks in basic education units using different tools that developed PC skills, as shown in Table 1.

Given the filter of criteria selected in Table 2, we observed that the skills addressed in the PC pillars, such as pattern recognition, logical reasoning, abstraction, etc., are being worked on through block programming, because works with different educational modalities and different pedagogical approaches are taking advantage of block programming to expand these skills. Reports of the works that dealt with: inclusive education, indigenous education, and regular basic education performing practices using tools with block programming, propagate the importance of programming for the development of PC.

Another important piece of data deals with the research question through which we analyzed the tools used, as shown in Graph 1. It is possible to see that $48 \%$ of the developed activities used the tool Scratch 1 and $29 \%$ from App Inventor ${ }^{2}$ tool. In this context, it was observed that these two tools were considered strategies that contributed to the teaching of block programming, as it was categorized from digital games to multidisciplinary projects such as: products for financial education in mathematics teaching, resulting from the scope of the learning developed through these tools.

Figure 1. Main Tools Used in Basic Education with Block Programming.

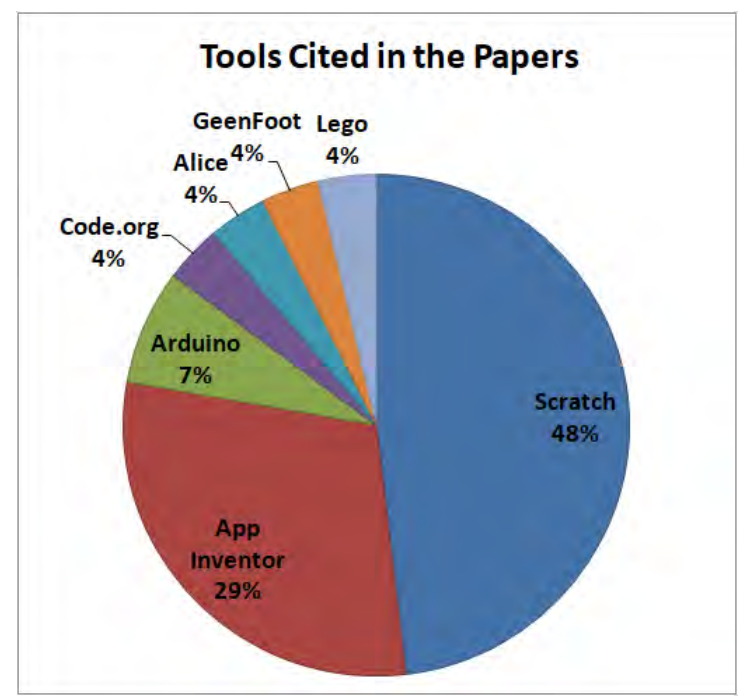

In its totality we obtained a total of 29 mapped papers, among which it was observed, as shown in Table 3, that most of the works were developed in the northeast region.

\footnotetext{
${ }^{1}$ Scratch is a programming language created in 2007 by MIT's Medium Lab. Since 2013 Scratch2 has been available online and as an application for Windows, OS X, and Linux. The source code for version 1.x is under the GPLv2 license. Available at: https://scratch.mit.edu.

${ }^{2}$ MIT App Inventor, also known as App Inventor for Android, is an open-source application originally created by Google, and currently maintained by Massachusetts Institute of Technology (MIT). It allows computer programming newcomers to create software applications for the operating system Android. Available at: https://appinventor.mit.edu.
} 
Table 3. Number of papers per region in Brazil.

\begin{tabular}{c|c|c|c|c}
\hline Regions & North & Northeast & Southeast & South \\
\hline All & 3 & 17 & 4 & 5 \\
\hline
\end{tabular}

We did not verify dated reasons why this phenomenon occurred, however, we can point out that most of the works involved partnerships between universities and schools. This finding also reveals that even though the BNCC deals with the insertion of the PC in basic education, the movement within the school is still considered small. This analysis leads to reflection on the subject that still generates much discussion about teacher training for the teaching of PC, and the practices that will be developed as a result of their knowledge with programming. In this context, the most used tools according to the data were indispensable for being free and considered easy to use in the reports described in the mapped works.

\section{Final considerations}

The result of the mapping considering the criteria of data extraction and the two most used tools, we conclude that free tools are artifacts that facilitate the activities, and that to meet the BNCC on PC in elementary school, block programming can be considered a primary strategy for the development of PC and an important methodology for the basic teaching of programming even in approaches with cross-cutting themes and different educational modalities, considering that the BNCC directs the PC to be inserted in elementary school in a multidisciplinary way.

\section{Future Work}

As a recommendation, we propose an expansion of the researched base by checking other bases (journals and events) not covered by the research, in order to increase the selection of studies, because in SLM we highlight the strategies used through tools that use block programming to develop educational practices. Thus, the block programming offer can be scaled both with digital tools and in the form using unplugged computing, as it covers all the competencies foreseen in the BNCC in accordance with the PC.

\section{References}

Amorim, Jadson et al. Integrating the App Inventor and Arduino Platforms in the Construction of a Humanoid. In: Annals of the Workshop of Computing in School. 2016. p. 786.

Bombasar, James et al. Tools for teaching-learning computational thinking: where is Alan Turing? In: Brazilian Symposium on Computers in Education (Simpósio Brasileiro de Informática na Educação-SBIE). 2015. p. 81.

Brasília, D. (2018). Base Nacional Comum Curricular. Available at: http://basenacionalcomum.mec.gov.br/images/BNCC_EI_EF_110518_versaofinal_site.pdf.

Brazil. Law of Directives and Bases of National Education. Law no. 9.394, of December $20,1996$.

Burnett, Margaret; Sheretov, Andrei; Rothermel, Gregg. Scaling up a" what you see is what you test" methodology to spreadsheet grids. In: Proceedings 1999 IEEE Symposium on Visual Languages. IEEE, 1999. p. 30-37.

Da Silva, Mozart Linhares; De Freitas, Josí Aparecida. A Base Nacional Comum Curricular and the Neoliberal Art of Governing Education In Brazil. Revista Educativa-Revista de Educação, v. 23, n. 1, p. 8097, 2021.

Leal, Lucas; Aita, Keylla Maria Sá Urtiga; Silva, Aline. Experience with the use of the Scratch Tool in the Therapy of Psychiatric Patients. In: Proceedings of the Workshop on Computing in School. 2019. p. 954-963.

Morais, Ceres Germanna Braga; Neto, Francisco Milton Mendes; Osório, António José Meneses. Difficulties and challenges of the algorithms and programming learning process in higher education: a systematic literature review. Research, Society and Development, v. 9, n. 10, p. e9429109287-e9429109287, 2020.

Oliveira Farias, Fernando Lucas de et al. Finance Math Game: An interdisciplinary ludic proposal for Teaching Financial Education with Scratch. In: Proceedings of the Workshop on Computing in School. 2019. p. 1359-1363. 
Oliveira, Manassés Vitorino; Rodrigues, Luciene Cavalcanti; Queiroga, Ana. Ludic didactic material: use of the Scratch tool to aid in the learning of programming logic. In: Anais do Workshop of Informatics at School. 2016. p. 359.

Petersen, Kai; Sairam, Vakkalanka \& Ludwik, Kuzniarz. Guidelines for conducting systematic mapping studies in software engineering: An update. Information and Software Technology 64. 2015. p 1-18.

Santos, Jarles Gomes et al. Gamification as a Methodology for the Development of BNCC General Competencies. In: Proceedings of the Workshop on Computing in School. 2019. p. 812-821.

Segundo, Plácido et al. COMPUTATIONAL THINKING: A strategy for teaching and promoting citizenship in indigenous basic education using free robotics and Scratch programming logic. In: Proceedings of the XXV Workshop on Computing at School. SBC, 2019. p. 1374-1378.

Wing, Jeannette M. Computational thinking. Communications of the ACM, v. 49, n. 3, p. 33-35, 2006. 